\title{
Multifunctional Lignin-Based Composite Materials for Emerging Applications
}

\author{
Chang Ma ${ }^{1,2}$, Tae-Hee $\mathrm{Kim}^{3}$, Kun Liư ${ }^{4}$ Ming-Guo Ma ${ }^{*}$, Sun-Eun Choi ${ }^{3 *}$ and \\ Chuanling Si**
}

${ }^{1}$ Research Center of Biomass Clean Utilization, Engineering Research Center of Forestry Biomass Materials and Bioenergy, Beijing Key Laboratory of Lignocellulosic Chemistry, College of Materials Science and Technology, Beijing Forestry University, Beijing, China, ${ }^{2}$ Material Science and Engineering College, Northeast Forestry University, Harbin, China, ${ }^{3}$ Department of Forest Biomaterials Engineering, College of Forest and Environmental Sciences, Kangwon National University, Chuncheon-si, South Korea, ${ }^{4}$ Tianjin Key Laboratory of Pulp and Paper, Tianjin University of Science and Technology, Tianjin, China

Lignin exhibited numerous advantages such as plentiful functional groups, good biocompatibility, low toxicity, and high carbon content, which can be transformed into composites and carbon materials. Lignin-based materials are usually environmentally

OPEN ACCESS

Edited by:

Xin Zhou,

Nanjing Forestry University, China

Reviewed by:

Bailiang Xue,

Shaanxi University of Technology,

China

Wei Xia,

Uppsala University, Sweden

*Correspondence:

Ming-Guo Ma

mg_ma@bjfu.edu.cn

Sun-Eun Cho

oregonin@kangwon.ac.kr

Chuanling Si

sichli@tust.edu.cn

Specialty section:

This article was submitted to

Bioprocess Engineering,

a section of the journal

Frontiers in Bioengineering and

Biotechnology

Received: 13 May 2021

Accepted: 25 May 2021

Published: 02 July 2021

Citation:

Ma C, Kim T-H, Liu K, Ma M-G,

Choi S-E and Si C (2021)

Multifunctional Lignin-Based Composite Materials for Emerging

Applications.

Front. Bioeng. Biotechnol. 9:708976.

doi: 10.3389/fbioe.2021.708976 friendly and low cost, and are widely used in energy storage, environment, electronic devices, and other fields. In this review article, the pretreatment separation methods like hydrothermal process are illustrated briefly, and the properties and categories of technical lignin are introduced. Then, the latest progress of lignin-based composites and lignin-derived carbon materials is summarized. Finally, the current challenges and future developments were suggested based on our knowledge. It is expected that this review paper favored the applications of composites and lignin-derived carbon materials in the future.

Keywords: lignin, composites, carbon, synthesis, applications

\section{INTRODUCTION}

Cellulose, lignin, and hemicellulose are the main chemical components of plant fiber raw materials (Li S.X. et al., 2019; Yang et al., 2019; Liu W. et al., 2020; Liu H. et al., 2021; Liu K. et al., 2021; Liu W. et al., 2021; Wang et al., 2021). Among these three components of lignocellulose, lignin is the only amorphous aromatic polymer (Figure 1A; Deuss et al., 2015; Xu J. et al., 2020; Ma et al., 2021b). Previously, the production of Kraft lignin and soda lignin was mainly used as a dye to provide a heat source for the burning section of the alkali recovery in the pulp and paper industry (Li et al., 2016; Xu et al., 2021). Given that lignin is a rich natural resource, increasing attention is paid to the research, development, and utilization of lignin in today's increasingly scarce resources (Upton and Kasko, 2016; Li X. et al., 2019; Li et al., 2021). The structure of lignin is relatively complex than other biomass; therefore, it has a broad research prospect to develop appropriate methods for separation and refinery of lignin, conduct detailed research, and then unitize it to prepare materials rationally (Ragauskas et al., 2014; Chen et al., 2016; Meng L.Y. et al., 2019; Chen et al., 2020b; Ma et al., 2020).

Lignin is composed of three kinds of structural units such as syringl unit (S), guaiacol unit $(\mathrm{G})$, and p-hydroxyphenyl unit (H) (Figure 1B; Decostanzi et al., 2019; Chen et al., 2020c; Shi and Ma, 2019; Liu K. et al., 2021). In the previous literatures, the lignin of softwoods is mainly G-type units; meanwhile, hardwoods are mainly G-type and S-type units. There are more abundant types of lignin in gramineous plants, including G, S, and H-type units. They are connected by ether bonds 
(about 60-70\%) and carbon-carbon bonds (about 30-40\%). Among them, all the alkyl-aryl ether bonds ( $\beta-O-4$ and $\alpha-O-4)$, the $\beta$ - $\beta$ ' linkages, and the $\beta$ - 5 linkages are predominant between above three structural units (Figure 1C; Zheng et al., 2021). The structure composition and interunit linkages of lignin are also closely related to the external factors such as the growing environment of plants. Therefore, the different structural units, different linkage, and the complex relationship between lignin and glycan in the cell wall endow lignin one of the most complex natural polymers in nature. Lignin molecules contained a variety of active functional groups both on the benzene ring and the side chain, including aliphatic hydroxyl $(\mathrm{Al}-\mathrm{OH})$, phenolic hydroxyl $(\mathrm{Ph}-\mathrm{OH})$, carboxyl $(-\mathrm{COOH})$, carbonyl $(-\mathrm{C}=\mathrm{O})$, and methoxy groups $\left(-\mathrm{OCH}_{3}\right)$, determining the chemical properties and reactivity of lignin. The chemical properties of lignin allow it and its derivatives to be used as materials for value-high. Furthermore, considering the high carbon content of lignin, it is also an ideal carbon material precursor (Shi and Ma, 2019). Lignin-derived carbon materials are widely used in various fields like energy storage, adsorbent, and catalyst carriers (Suhas et al., 2007; Saha et al., 2014).

In this review article, we focus on the current achievements of lignin-based materials. The categories of lignin were introduced briefly. Then, the lignin-based materials like lignin-based hydrogels, flocculants, and resin adhesive, and lignin-plastic composites are summarized. In addition, the lignin-derived carbon materials such as activation carbon, carbon fibers, and carbon dots are discussed in detail. Finally, the existed problems and future trends of lignin-derived materials are proposed as well. It is expected that the lignin-based materials are promising applications in various fields.

\section{THE SEPARATION METHODS AND COMPOSITIONS OF LIGNIN}

Lignocellulose is one of the most abundant biomass resources, mainly composed of $40-50 \%$ cellulose, $20-30 \%$ hemicellulose, and 25-35\% lignin (Lievonen et al., 2016). According to statistics, about five thousand million tons of lignin has been produced globally every year (Chio et al., 2019; Meng Y. et al., 2019). Chemical structures of lignin varied among different plants species, such as softwoods, hardwoods, and grasses (Boerjan et al., 2003). Lignin does not stand for a single substance, but for a group of substance that have common properties in plants (Garcia Calvo-Flores and Dobado, 2010). The separation of lignin, based on the raw materials, can be divided into three types of separation from plant raw materials, separation from pulp, and separation from pulp waste liquid. Based on the separation principle, the first one is to remove the cellulose and hemicellulose by dissolution, leaving the insoluble residue of lignin. Meanwhile, the second is to dissolve the lignin, leave the insoluble residue of cellulose and hemicellulose, and recover lignin from the solution (Zhao and Abu-Omar, 2021). Bjorkman proposed a classic method for separating lignin by extraction after ball milling as early as 1953, resulting in the production of milled wood lignin. The milled wood lignin is closed to natural lignin, but in view of the yield is low, so it is often used to study the structure of lignin (Wang et al., 2009). Therefore, it is always a challenge to find a clean and efficient process to separate and recover lignin components with high yield and high structural integrity. Now, the research on biomass refining became a hot direction, which is to separate and extract lignin from biomass feedstock by pretreatment to make it easier for subsequent conversion and further applications. Numerous efforts have been devoted to find the potential pretreatment methods, and various methods have been explored, such as physical, chemical, physicochemical, and biological methods (Hochegger et al., 2019). For example, hydrothermal pretreatment is an environmental-friendly method for biomass separation. Sun et al. (2014) developed an integrated strategy including hydrothermal pretreatment and alkaline posttreatment, studied the changes of linkages during process, and obtained the highest yield of lignin up to $79.3 \%$. These findings are beneficial to understand depolymerization and maximize the potential utilizations of lignin. In addition, there have been noticeable advances using novel solvents like ionic liquids, which are called "green solvents." Since no toxic chemicals are formed and almost $100 \%$ can be recycled, it is considered that the ionic liquid pretreatment is a green solvent. Sun et al. (2019) applied a microwave-assisted ionic liquid approach to decrease the resistance of biomass in biorefinery and led to a high yield of lignin and efficient extraction of biomass. Deep eutectic solvent (DES) pretreatment is another new blooming green strategy for reducing biomass recalcitrance. Shen et al. (2019) employed biomass-derived DES including biomass-derived chemicals to deconstruct the structure of Eucalyptus for lignin valorization. Ma et al. (2021a) used microwave-assisted DES pretreatment to improve the lignin extractability and valorization of poplars. After DES pretreatment, the enzymatic saccharification rations were significantly increased, indicating that this microwaveassisted DES method could reduce the biomass recalcitrance and promote the lignin valorization. There have been series of review papers that summarize lignin extracted methods (Azadi et al., 2013; Chio et al., 2019). Herein, we mainly discuss the common industrial lignin.

In the paper industry, the four main methods of separating technical lignin (or pulping) are the Kraft pulping, sulfite pulping, soda pulping, and organosolv pulping processes. The obtained lignin types are Kraft lignin, lignosulfonate, soda lignin, and organosolv lignin, respectively (El Mansouri and Salvado, 2006). Due to the different processing methods, these four technical lignins have different structures, compositions, and properties. Kraft lignin is the residue of sulfate pulping in paper production, which is precipitated by adjusting the $\mathrm{pH}$ value of black liquor (Huang et al., 2017). The structure of Kraft lignin is highly modified and soluble in alkaline solution and organic solvents with high polarity (Chakar and Ragauskas, 2004). Lignosulfonate is sulfonated lignin, which is removed from the wood raw materials by sulfite pulping. Lignosulfonate is soluble in acidic solution, alkaline solution, and organic solvents with high polarity. Even though they contain sulfur, these two kinds of lignin have different characteristics, and the molecular weight of lignosulfonate is 

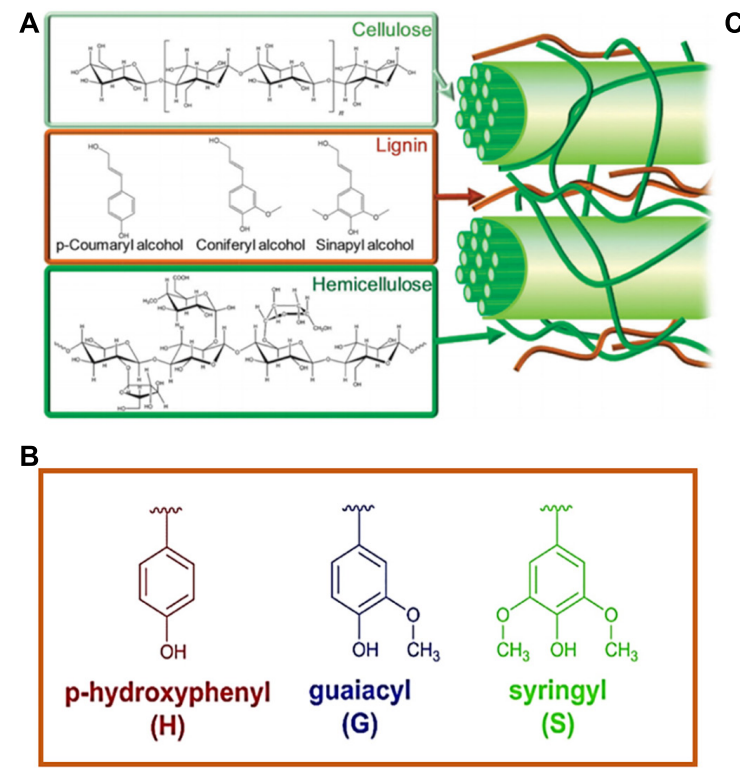

C

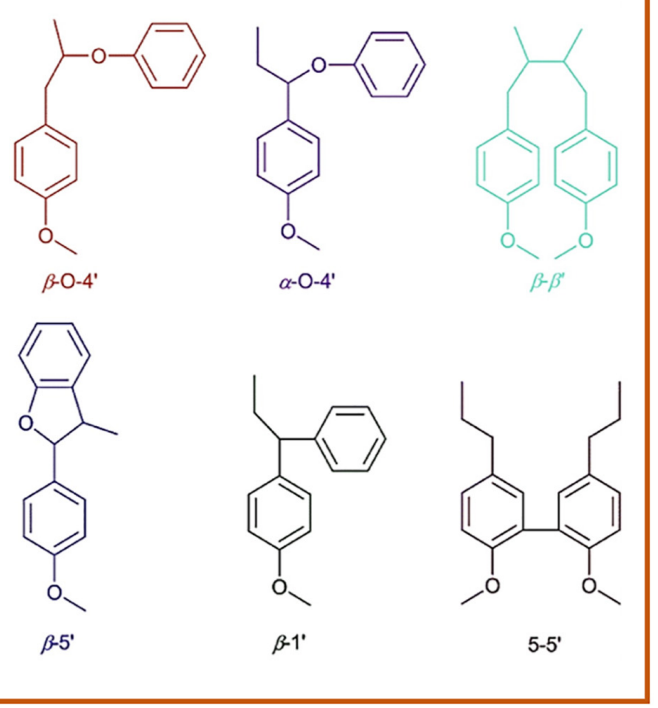

FIGURE 1 | (A) Typical structure of lignocellulose (Zhu et al., 2020). (B) Precursors and (C) common interunit linkages (Luis Espinoza-Acosta et al., 2018).

higher (Vishtal and Kraslawski, 2011). Soda lignin (or Alkaline lignin) is generally free of sulfur, which has a relatively lower molecular weight (Woermeyer et al., 2011). Organic solvents lignin is collected by organosolv pulping process, which has the characteristics of high purity, high homogeneity, and low molecular weight (Li and Takkellapati, 2018; Yu and Kim, 2020). However, the process includes the necessary solvent recovery steps, increasing the cost (Zhao and Abu-Omar, 2021).

\section{THE FABRICATION AND PROPERTIES OF LIGNIN-BASED MATERIALS}

Owing to its good biocompatibility, ecological friendliness, and low toxicity, lignin is widely explored for high-value materials instead of burning (Si, 2019; Huang et al., 2020; Liu R. et al., 2020). The aromatic properties also make it possible to replace phenol to prepare phenolic resin adhesives (Pang et al., 2020; Pei et al., 2020). Herein, the synthesis and properties of lignin-based materials with various applications are described.

\section{Lignin-Based Hydrogels}

Hydrogel is a kind of hydrophilic three-dimensional network gel, which can swell and hold large amounts of water. Forest biomass materials such as cellulose and hemicellulose are widely used in the preparation of hydrogels (Liu et al., 2017; Du et al., 2019; Li et al., 2020). Moreover, lignin is in its infancy as strength modifier, adhesive agents, or other functional fillers in hydrogels for lignin fractionation, wearable electronics, UV shielding, and biomaterials (Thakur and Thakur, 2015). Dai et al. (2019) fabricated a lignin-contained cellulose hydrogel for lignin fractionation. In this hydrogel, alkaline lignin was employed to play as a functional crosslinker to simultaneously improve the mechanical performances and realize specific absorbed or filtered. This lignin-cellulose hydrogel showed a reliable way to integrate lignin materials and lignin fractionation. Han et al. (2021) developed a polyvinyl alcohol (PVA) hydrogel with lignin-silver hybrid nanoparticles, which exhibited exceptional compressibility. As a strength modifier of hydrogel, lignin-silver hybrid nanoparticles provided strong hydrogen bonds and facilitated the electron transfer. Considering these outstanding traits of this PVA/ligninsilver hybrid nanoparticle hydrogel, this hydrogel could be used as a pressure-sensitive sensor to monitor signals. After demethylation, the phenolic hydroxyl groups of lignin have been released, which not only made the lignin with adhesion property but also improved the reducibility. Qian et al. (2021) took full advantage of this to reduce graphene oxide and develop a catechol lignin/reduced graphene oxide/sodium alginate/polyacrylamide double network hydrogel with integrated conductive, adhesive, and UV-blocking performance. The obtained hydrogel exhibited great potential in flexible electronic skin. Gao et al. (2021) designed a nanosilver immobilized glycine decorated lignin hydrogel as a catalyst, which showed outstanding catalytic performance of $\mathrm{p}$-nitrophenol reduction. Amino modified lignin hydrogel networks played a role for catalyst carrier with abundant anchoring sites to disperse and stabilize the silver nanoparticles. After 10 cycles, the obtained catalyst can still maintain a catalytic efficiency of $98 \%$, and there is no obvious collapse of the structure as well as the leaching of nanosilver can be ignored.

For the biomedical field, Zhang et al. (2020) assembled a biomimetic lignin/poly(ionic liquids) composite hydrogel by supramolecular interactions for the application of wound dressing. The resultant hydrogel exhibited satisfying 
mechanical strength, self-healing properties, bactericidal activity, and anti-oxidant activity. Lignin as reinforcement and antioxidant improved the mechanical enhancement and antioxidant activity of the hydrogel. Besides, lignin-based hydrogels have been used for the controlled release of drug (Witzler et al., 2018). Borisenkov et al. (2016) synthesized a hemicellulose and lignin composite hydrogel for drug delivery. Pectin was embedded in the hydrogel to form hydrophilic supramolecular complexes, which was employed to deliver $\beta$-glucuronidase and estrogens.

In addition, due to the changes of solubility, lignin can be used as $\mathrm{pH}$-sensitive ingredient to form $\mathrm{pH}$-responsive hydrogel in shape memory and controlled release (Figueiredo et al., 2017; Jin et al., 2018). Dai L. et al. (2020) prepared an alllignin-based $\mathrm{pH}$-stimuli-responsive hydrogel for the actuator. Herein, the kraft lignin was crosslinked with poly(ethylene glycol) diglycidyl ether to build this lignin hydrogel. As shown in Figure 2A, the lignin-based hydrogel bended spontaneously as the $\mathrm{pH}$ changes. Therefore, a mimetic behavior to hook up a wire has been achieved by adjusting $\mathrm{pH}$ (Figure 2B). These studies demonstrated that the use of lignin in hydrogel can contribute to areas such as electronics manufacturing, wearable devices, drug delivery, and actuators.

\section{Lignin-Phenol-Formaldehyde Resin Adhesive}

From the perspective of the structural characteristics of lignin, it is also a high-value approach to prepare ligninphenol-formaldehyde resin adhesive. Pang et al. (2017) studied the relationships between structure and property of two technical lignins in synthesis and performance of lignin-phenolformaldehyde resin adhesive. They were obtained from acidic and alkaline organosolv pulping of bamboo. After purification, they were both characterized thoroughly, and the structural features were compared. The results showed that the long-chain hydrocarbon derivatives presented in lignin would affect the synthesis of lignin-phenol-formaldehyde resin.
Depolymerization, activation, phenolate, and demethylation are the common pre-treatment processes to release the phenolic hydroxyl group of lignin (Naseem et al., 2016; Wang et al., 2018; An et al., 2019; Gan and Pan, 2019). For example, Ma et al. (2018) investigated a catalytic oxidative depolymerization process for increasing the content of phenolic hydroxy groups of Kraft lignin. Hydrogen peroxide and copper sulfate were used as catalysts in this process. After reaction, the phenolic hydroxyl content increased from 1.55 to $2.66 \mathrm{mmol} \mathrm{g}^{-1}$, and both the molecular weight and polydispersity decreased. The resultant lignin was used to synthesize lignin-phenol-formaldehyde resin with $50 \%$ substitution rate, whose various indexes all achieved the national standards. Base-catalyzed depolymerization of softwood Kraft lignin was used to release the phenolic hydroxyl of lignin to substitute phenol in resins (Solt et al., 2018). Modified renewable lignin-based phenols could replace phenol even at a high degree of substitution of 70\%. As shown in Figure 3, $\mathrm{Li}$ et al. (2018) employed $\mathrm{NaOH} /$ urea aqueous solution to depolymerize the alkali lignin to prepare low molecular weight lignin derivatives, so as to further prepare lignin-phenolformaldehyde resin. After depolymerization treatment process, phenyl-propane trimers were mainly obtained, and the phenolic hydroxyl group content increased from 0.07 to $0.12 \mathrm{mmol} \mathrm{g}^{-1}$. The resultant depolymerized alkali lignin-phenol-formaldehyde resin displayed fast curing rate, low formaldehyde emission, and high bonding strength. Microbes such as the brown-rot, white-rot, and soft-rot fungi were also investigated for the demethylation of Kraft lignin (Venkatesagowda and Dekker, 2020). Demethylation by the action of enzymes removed the $O$-methyl/methoxy of lignin and produced the demethylated Kraft lignin enriched in vicinal-hydroxyl groups, which has potential in lignin-phenol-formaldehyde resin. These studies demonstrated that the depolymerized lignin derivatives can replace phenol in the preparation of phenolic resin.

\section{Lignin-Based Flocculants}

Lignin can be employed to treat wastewater. However, most of them suffered from poor solubility, chemical inactivity, and
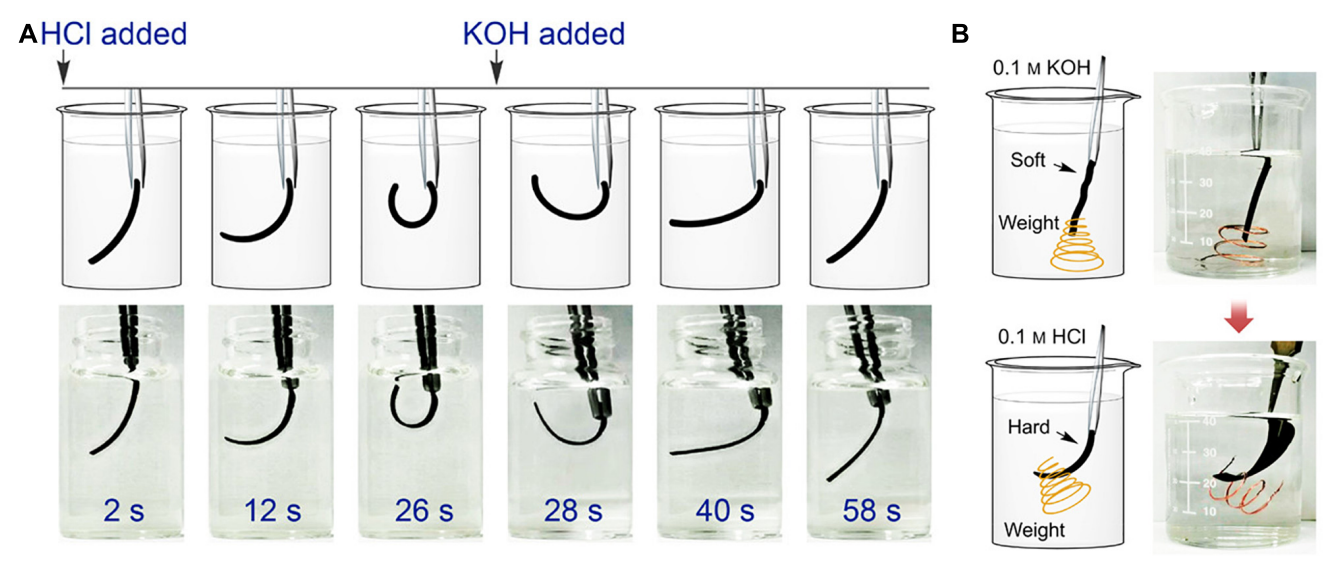

FIGURE 2 | (A) pH-responsive deformation of the lignin-based hydrogel by adding $\mathrm{HCl}$ and $\mathrm{KOH}$ solution; (B) Actuating performance of the lignin-based hydrogel for being hooked up (Dai L. et al., 2020). 


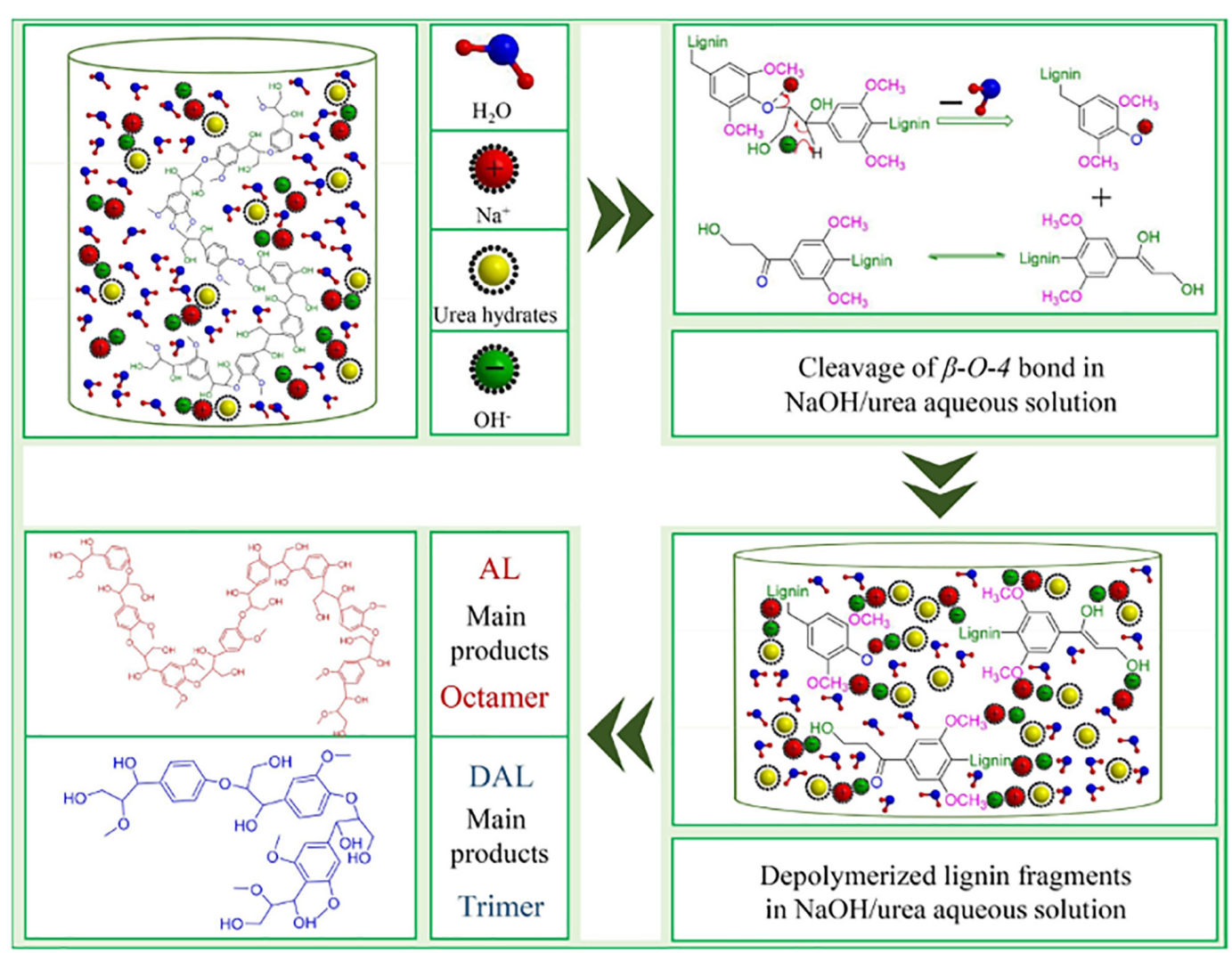

FIGURE 3 | Schematic diagram of $\mathrm{NaOH} /$ urea aqueous solution to depolymerize the alkali lignin to prepare low molecular weight lignin derivatives (Li et al., 2018).

low molecular weight. Therefore, various chemical modification methods have been utilized to lignin to improve the flocculation performance (Wang et al., 2020b). Guo et al. (2018) developed an environmentally friendly lignin-based flocculant with improved flocculation by grafting the cationic acrylamide and dimethyl diallyl ammonium chloride monomers onto the alkaline lignin. The flocculation performance of the obtained lignin-based flocculant was low affected by $\mathrm{pH}$. Moreover, the addition of $\mathrm{Ca}^{2+}$ and $\mathrm{Mg}^{2+}$ could significantly enhance the flocculation performance. Chen et al. (2020a) employed enzymatic hydrolysis lignin as raw materials, using polyacrylamide and methylacryloyloxyethyltrimethyl ammonium chloride as graft agent to synthesize a lignin-based cationic flocculant (L-CPA). The resultant L-CPA could selfassemble into octopus-like nanospheres, which endowed the high flocculation efficiency under the $\mathrm{pH}$ condition of 5-9. A small flocculant could be used to flocculate kaolin suspension. Such cheap, environmentally friendly, and technically feasible lignin-based flocculant exhibited a broad prospect in wastewater treatment process. Wang et al. (2020a) designed a lignin-based flocculant by mild copolymerization of lignosulfonate and [2-(methacryloyloxy) ethyl] trimethylammonium chloride solution. By changing the reaction conditions, two classes of flocculant were obtained, which were suitable for simulated dye wastewater (removal rate up to 95\%), kaolin (turbidity removal rate up to $99.2 \%$ ), and Escherichia coli suspensions (bacterial removal rate up to 97.5\%), respectively. Anionic lignin-based flocculant was also prepared (Aldajani et al., 2021). Aldajani et al. (2021) prepared a hydrolyzed anionically modified ligninacrylamide flocculant and investigated the different properties of polymer on the suspension's attributes such as zeta potential, relative turbidity, flocs strength, and recoverability. Through the combination of many of its functional groups, namely, amide, carboxyl, and hydroxyl, it is observed that this lignin-based flocculant had a deeper adsorption on alumina particles than other polymers. These studies exhibited that the production and application of high-efficiency lignin-based flocculants are of great significance for resource conservation, low carbon footprint, and wastewater reuse.

\section{Lignin-Plastic Composites}

In past decades, billions of tons of non-biodegradable plastics have been produced, which is a significant source of pollution. As an abundant natural polymer, lignin could be integrated into plastics to fabricate high-value biodegradable materials with economic competitiveness (Sen et al., 2015; Kazzaz et al., 2019). Therefore, the preparation of composite materials by mixing lignin with various plastics had attracted attention. For example, Cerro et al. (2021) produced a poly(lactic acid) (PLA)/lignin nanoparticle composite containing cinnamaldehyde (Ci) for packaging and biomedical applications, which exhibited a better UV-light barrier property and biodegradable performance. 
Herein, lignin nanoparticles are used as fillers to enhance the mechanical strength of polymer composites. The toxicity of PLA/lignin composites has been studied as well, and the results showed normal blood parameters after a single dose of composites. Xiong et al. (2020) produced a composite by blending poly(butylene adipate-co-terephthalate) (PBAT) and Eucalypt hydrothermal lignin (Figure 4A). Two strategies were followed to improve the performance of composites, including methylated lignin replaced neat lignin as filler, and twin-screw extrusion was used as preparation method. The obtained PBAT/lignin composite materials exhibited a price advantage, in which the cost was significantly reduced by $36 \%$.

Three-dimensional (3D) printing is a method of shape rendering. The ideal materials for $3 \mathrm{D}$ printing need to have good extrudability. The unique structures of lignin such as ether groups, $\beta-O-4^{\prime}$ linkages, and oxygenated aromatic bonds endow it suitable to incorporate into conventional plastic materials to build hybrid materials by $3 \mathrm{D}$ printing with more environmentally friendly and better printability (Nguyen et al., 2018b). A study reported that organosolv hardwood lignin was mixed with nylon as $3 \mathrm{D}$ printing ink, and the lignin was found to improve the printability by reducing the melt viscosity and enhance the stiffness and tensile strength of the structure (Nguyen et al., 2018a). The proposed mechanism was lignin domains forming hydrogen bonds with the plastic matrix. This study came up with a new strategy of using biomass lignin as a feedstock for valuable 3D printing materials. Sutton et al. (2018) reported renewable, modified lignin-containing photopolymer resins for $3 \mathrm{D}$ printing by stereolithography. Compared to conventional photoactive resins, the lignin-containing resins displayed satisfied ductility, in which the lignin content can reach up to $15 \%$. High print quality and visual clarity were obtained as shown in Figure $\mathbf{4 B}$ of the photographs of formulations with different lignin content. These studies showed that lignin is cheap and eco-friendly as a feedstock for plastic composites.

\section{LIGNIN-DERIVED CARBON MATERIALS}

Carbon materials were extensively applied in numerous fields such as energy storage and conversion, environmental applications, and catalyst (Dong et al., 2020). Generally, carbon materials are derived from petroleum-based chemicals by carbonization treatment, which is non-renewable, non-cyclable, and less environmentally friendly (Shi and Ma, 2019). Lignins are ideal raw materials as carbon precursors due to the low cost and high carbon content. It is of great significance to protect the environment, save resources, and develop the economy harmoniously.

\section{Lignin-Derived Activated Carbons}

Due to the high cost of producing activated carbon from coal, the production of activated carbon from lignocellulosic feedstock has attracted much attention (Jiao et al., 2021). A series of chemical activators like $\mathrm{KOH}$ and $\mathrm{K}_{2} \mathrm{CO}_{3}$ was adopted. For example, $\mathrm{He}$ et al. (2021) chose lignin-based pitch from black liquor as carbon precursor and $\mathrm{KOH}$ as chemical activator to synthesize porous activated carbon materials. The activation temperature on the lignin-derived active carbon was also explored. It was found that the maximum specific surface area and total pore volume reached the values of $3652 \mathrm{~m}^{2} \mathrm{~g}^{-1}$ and $2.35 \mathrm{~cm}^{3} \mathrm{~g}^{-1}$ under the activation temperature of $850^{\circ} \mathrm{C}$. In addition, the ability of the lignin-derived activated carbon to absorb gaseous benzene has also been studied, and the adsorption performance exhibited that the carbon could be a good candidate for absorbing. As shown in Figure 5, Xu Q. Q. et al. (2020) employed sodium lignosulfonate (SLS) and ionic liquid ([Amim $] \mathrm{Cl})$ to produce a new polymeric ionic liquid [Amim]LS and $\mathrm{NaCl}$. The mixture was used as a precursor to prepare $\mathrm{N}$-doped porous carbon material via direct carbonization without other activations. Herein, $\mathrm{NaCl}$ played the role of temple and activation agent. The obtained lignin-based porous carbon achieved a nitrogen content of $4.68 \%$. Under the carbonization temperature of $700^{\circ} \mathrm{C}$, a good energy density of
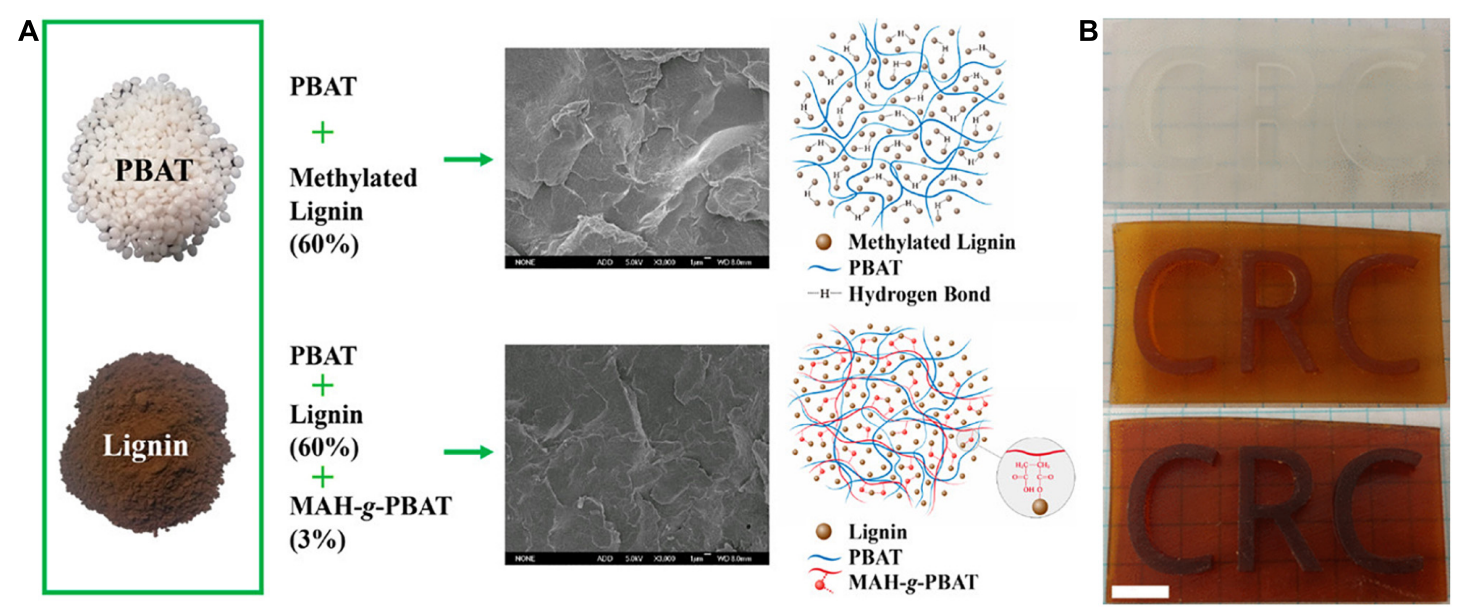

FIGURE 4 | (A) Preparation of a composite by blending PBAT and Eucalypt hydrothermal lignin via two strategies (Xiong et al., 2020); (B) Digital photos of 0\%, 5\%, and $10 \%$ lignin (from top to bottom) exhibiting the effect on print quality (Sutton et al., 2018). 


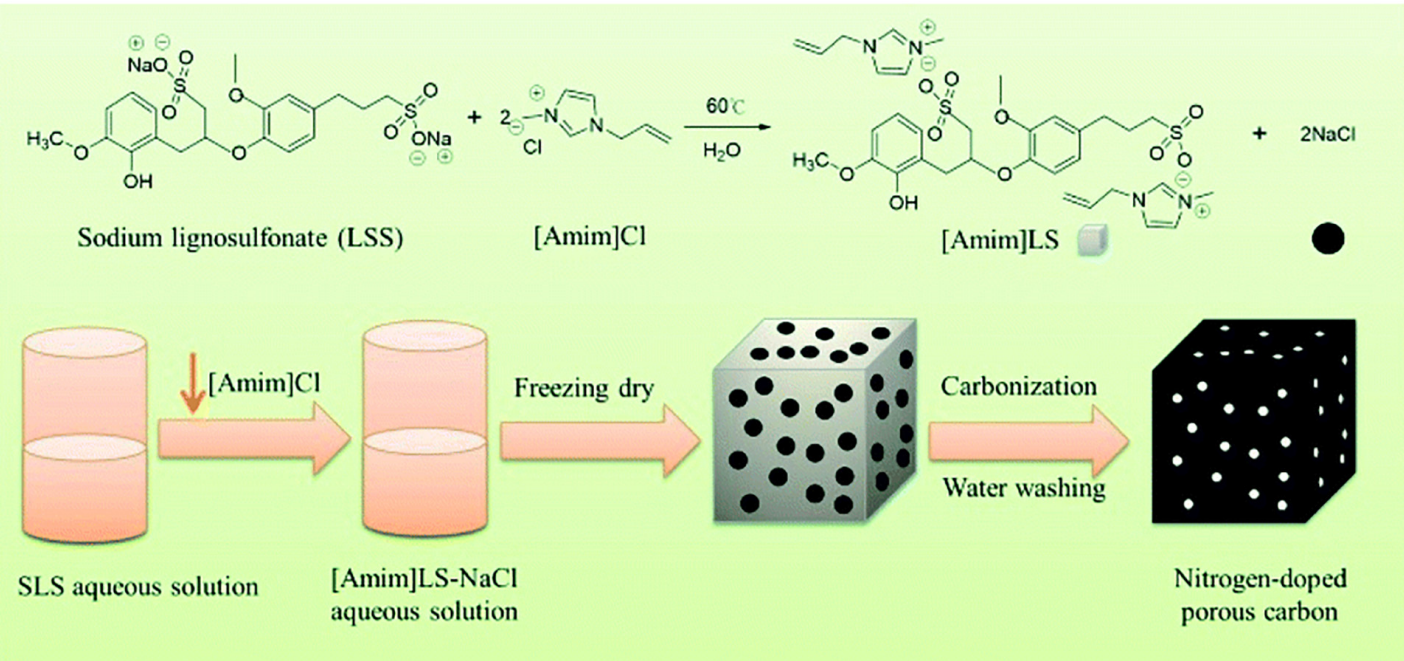

FIGURE 5 | Schematic diagram of [Amim]LS precursors for N-doped porous carbon material fabrication (Xu Q. Q. et al., 2020).

$7.99 \mathrm{Wh} \mathrm{kg}^{-1}$ at the power density of $25 \mathrm{~W} \mathrm{~kg}^{-1}$ and cycling stability of $90.3 \%$ after 20000 cycles are shown. There are also some studies on the lignin-derived carbon with hierarchical porous architectures (Zhang et al., 2015a,b). Xi et al. (2021) obtained lignin-derived porous carbons with microstructural characteristics, high graphitization, high specific surface area, and hierarchical porosity for fabrication composites to alleviate the expansion and pulverization phenomena of lithium-ion batteries. Such lignin-derived porous carbons facilitated dispersing/coating of $\mathrm{SnO}_{2}$ and increased the reversible specific capacity from 64 to $620 \mathrm{mAh} \mathrm{g}^{-1}$. Wan et al. (2021) converted lignin to carbon materials with 3D hierarchical porous structures. After phosphoric acid plus hydrogen peroxide (PHP) oxidation pretreatment and $\mathrm{KOH}$ activation, the carbonized lignin reached a high surface area of $3094 \mathrm{~m}^{2} \mathrm{~g}^{-1}$ and pore volume of $1.72 \mathrm{~cm}^{3}$ $\mathrm{g}^{-1}$. The electrochemical measure results showed that the ligninbased carbon achieved a specific capacitance of $352.9 \mathrm{~F} \mathrm{~g}^{-1}$ at $0.5 \mathrm{~A} \mathrm{~g}^{-1}$, indicating an outstanding rate performance of this carbon electrode.

\section{Lignin-Derived Carbon Fibers}

Lignin can be used as a cheap precursor in the preparation of carbon fibers instead of petroleum-based polymers by electrospinning technique and carbonization (Garcia-Mateos et al., 2019). Lignin-based carbon fibers with different functions can be obtained by adjusting the parameters of electrospinning, the template selected, and the materials loaded. For example, Ma et al. (2021c) prepared carbon nanofibers using lignin and polyvinylpyrrolidone as carbon precursor by electrospinning, peroxidation, carbonization, and pickling processes. Zinc nitrate hexahydrate was added and pyrolyzed to produce zinc oxide, which was used as a template to produce abundant micropores, resulting in the high specific surface area of $1363 \mathrm{~m}^{2} \mathrm{~g}^{-1}$. In view of the high specific surface area and abundant N/O groups, these lignin-derived carbon fibers with a specific capacitance of $289 \mathrm{~F} \mathrm{~g}^{-1}$ were seen as potential candidates for supercapacitor electrodes. Furthermore, the assembled symmetrical supercapacitor displayed outstanding cycling stability. Liu and Ma (2020) employed lignin as a renewable carbon source with polyacrylonitrile (PAN) and urea to prepare $\mathrm{N}$-doped carbon nanofibers and then coated with polyaniline (PANI) for energy storage. The obtained lignin-based carbon fiber electrode displayed exceptional properties, including large specific surface areas of $483.1 \mathrm{~m}^{2}$ $\mathrm{g}^{-1}$, uniform pore size distribution of $9.1 \mathrm{~nm}$, and specific capacitance up to $199.5 \mathrm{~F} \mathrm{~g} \mathrm{~g}^{-1}$ at $1 \mathrm{~A} \mathrm{~g}^{-1}$. Eighty-two percent of the initial capacitance was maintained after 1000 charge/discharge at $4 \mathrm{~A} \mathrm{~g}^{-1}$. Dai Z. et al. (2020) developed a $\mathrm{N}, \mathrm{O}$ co-doped carbon nanofibers (E-CNFs) from waste lignin and PAN by facile esterification and electrospinning method. The lignin esterification reaction was displayed in Figure 6, and the resultant esterified lignin had a low glass transition temperature for higher heteroatom content and better wettability of carbon nanofibers. E-CNF electrode exhibited a high capacitance of $320 \mathrm{~F} \mathrm{~g}^{-1}$ at a current density of $1 \mathrm{~A} \mathrm{~g}^{-1}$. An outstanding energy density of $17.92 \mathrm{Wh} \mathrm{kg}^{-1}$ at the power density of $800 \mathrm{~W} \mathrm{~kg}^{-1}$ was achieved by E-CNF symmetric supercapacitors.

In addition to energy storage, lignin-derived carbon fibers have been used in the field of catalysis as well. Lignin-based Pt supported carbon fiber electrocatalysts were prepared for alcohol electro-oxidation (Garcia-Mateos et al., 2017). Lignin/ethanol/phosphoric acid/platinum acetylacetonate solutions were chosen as precursors for electrospinning. After thermostabilization and carbonization at $900^{\circ} \mathrm{C}$, carbon fibers with porous structure and Pt particle loading were obtained. Among them, the addition of phosphorus improved the oxidation resistance, avoided the oxidation of the ligninbased carbon fibers in the preparation process, and led to the 


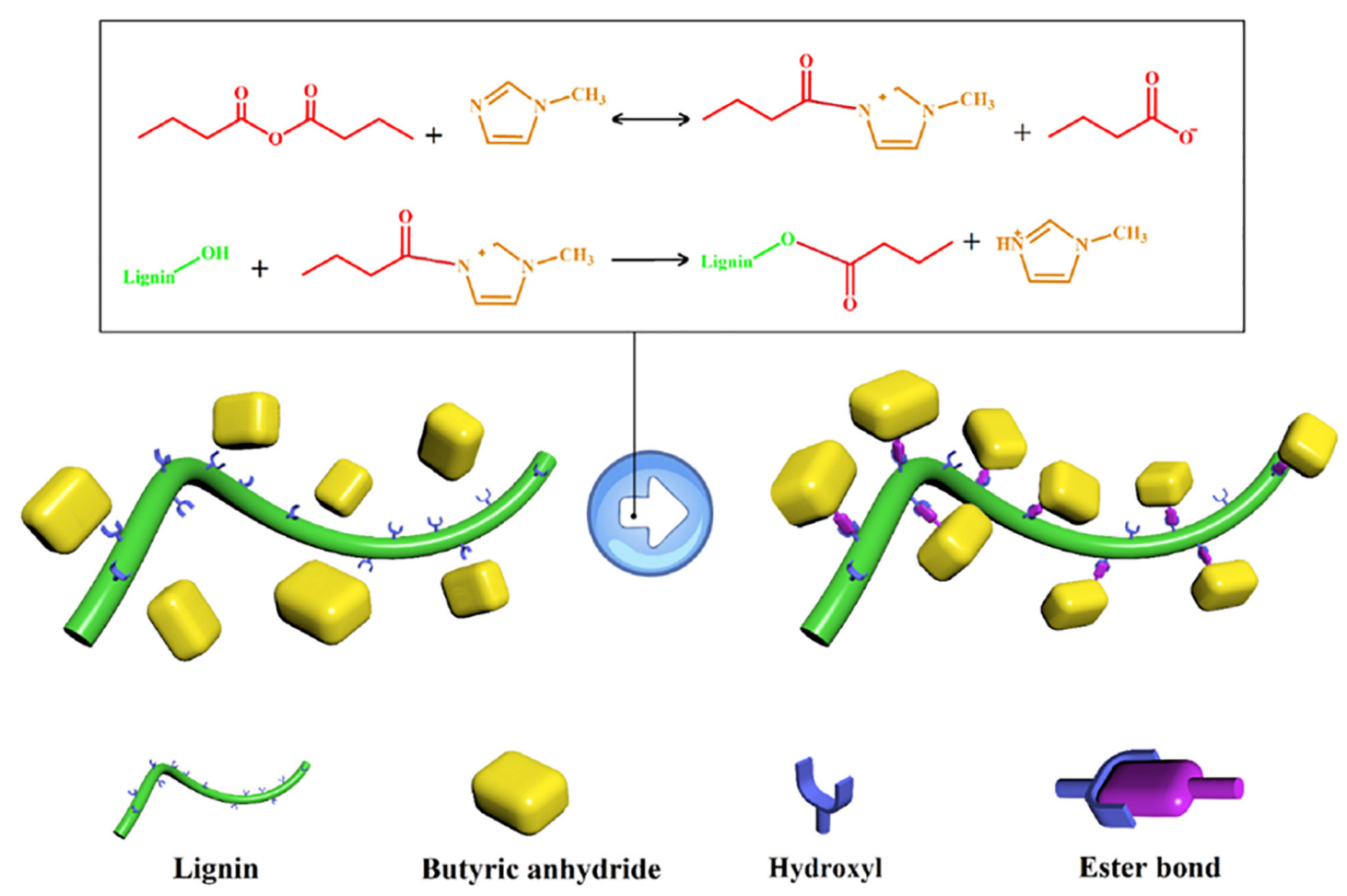

FIGURE 6 | Illustration diagram of lignin esterification reaction (Dai Z. et al., 2020).

generation of microporous architectures, which were beneficial to enhance the catalyst performance in the electro-oxidation of methanol and ethanol.

\section{Lignin-Derived Carbon Dots}

Carbon dot is a novel type of carbon nanomaterial, which was found in 2004 (Xu et al., 2004; Kang et al., 2020). Zhang et al. (2019) prepared carbon quantum dots with bright green fluorescence by a simple one-pot route. Alkali lignin was employed as a precursor. Chao et al. (2021) employed ligninderived carbon dots as photothermal thermogenesis materials to enhance wood-derived evaporation system. Herein, the ligninderived carbon dots were obtained by hydrothermal method. An evaporation performance of $1.18 \mathrm{~kg} \mathrm{~m}^{-2}$ and efficiency up to $79.5 \%$ were achieved. Yang et al. (2020) developed a green approach to prepare sulfur-doped carbon dots by hydrothermal treatment of lignin. The obtained lignin-derived carbon dots possessed sulfur-containing groups, exhibiting good fluorescence with a quantum yield up to $13.5 \%$ and outstanding stability in acidic environments with a wide $\mathrm{pH}$ range of $0-5.0$. Therefore, this lignin-derived carbon dots were successfully used in detection of Sudan I in acidic conditions.

\section{CONCLUSION AND PERSPECTIVES}

With the intensive investigation of lignin-based materials, the great development potential has been revealed in various fields. More and more efforts should be devoted on ligninbased materials and lignin-derived carbon materials. Further perspectives in lignin-based materials and lignin-derived carbon materials are proposed as follows.

(1) The low reactivity, solubility, and compatibility with conventional polymers of technical lignin enhance the difficulty of lignin to be a candidate to fabricate materials. Through chemical modification and careful design, these problems are partially or fully worked out, which expands the application of lignin in composite materials.

(2) Lignin does not stand for a single substance, but for a group of substances that have common properties in plants. Lignin is heterogeneous in nature, and it usually has heterogenous molecular weights, different functional groups, and different proportions of structural units. It is not conducive to repeatability, uniformity, and scalability of lignin-based materials. The obtained uniform lignin product via fractionation process may be one of the solutions for this problem.

(3) For lignin-derived activated carbon materials, chemical activators such as $\mathrm{KOH}$ and $\mathrm{H}_{3} \mathrm{PO}_{4}$ are often used to increase the specific surface area and the number of pores. However, most of these chemical activators are highly corrosive to the instrument and not recoverable. Therefore, it is vital to adopt green activators or design physical approaches for preparation of lignin-derived activated carbon. 
(4) The morphologies of lignin-derived carbon materials are always disordered and uncontrollable. It is necessary to design hierarchical porous architectures according to different applications.

(5) For lignin composite materials, more advanced technologies and strategies should be developed, like 3D printing and screen process. In addition, other applications of lignin-derived materials should also be designed, such as nanogenerators, thermal management, biomedical field, and so on.

\section{AUTHOR CONTRIBUTIONS}

CM, KL, and M-GM: investigation. T-HK, S-EC, and CS: supervision. CM and M-GM: writing - original draft. M-GM,

\section{REFERENCES}

Aldajani, M., Alipoormazandarani, N., Kong, F., and Fatehi, P. (2021). Acid hydrolysis of kraft lignin-acrylamide polymer to improve its flocculation affinity. Sep. Purif. Technol. 258:117964. doi: 10.1016/j.seppur.2020.11 7964

An, L., Si, C., Wang, G., Sui, W., and Tao, Z. (2019). Enhancing the solubility and antioxidant activity of high-molecular-weight lignin by moderate depolymerization via in situ ethanol/acid catalysis. Ind. Crops Prod. 128, 177185. doi: 10.1016/j.indcrop.2018.11.009

Azadi, P., Inderwildi, O. R., Farnood, R., and King, D. A. (2013). Liquid fuels, hydrogen and chemicals from lignin: a critical review. Renew. Sustain. Energy Rev. 21, 506-523. doi: 10.1016/j.rser.2012.12.022

Boerjan, W., Ralph, J., and Baucher, M. (2003). Lignin biosynthesis. Annu. Rev. Plant Biol. 54, 519-546. doi: 10.1146/annurev.arplant.54.031902.134938

Borisenkov, M. F., Karmanov, A. P., Kocheva, L. S., Markov, P. A., Istomina, E. I., Bakutova, L. A., et al. (2016). Adsorption of beta-glucuronidase and estrogens on pectin/lignin hydrogel particles. Int. J. Polym. Mater. Polym. Biomater. 65, 433-441. doi: 10.1080/00914037.2015.1129955

Cerro, D., Bustos, G., Villegas, C., Buendia, N., Truffa, G., Godoy, M. P., et al. (2021). Effect of supercritical incorporation of cinnamaldehyde on physical-chemical properties, disintegration and toxicity studies of PLA/lignin nanocomposites. Int. J. Biol. Macromol. 167, 255-266. doi: 10.1016/j.ijbiomac. 2020.11.140

Chakar, F. S., and Ragauskas, A. J. (2004). Review of current and future softwood kraft lignin process chemistry. Ind. Crops Prod. 20, 131-141. doi: 10.1016/j. indcrop.2004.04.016

Chao, W. X., Li, Y. D., Sun, X. H., Cao, G. L., Wang, C. Y., and Ho, S. H. (2021). Enhanced wood-derived photothermal evaporation system by in-situ incorporated lignin carbon quantum dots. Chem. Eng. J. 405:126703. doi: 10. 1016/j.cej.2020.126703

Chen, N., Liu, W. F., Huang, J. H., and Qiu, X. Q. (2020a). Preparation of octopuslike lignin-grafted cationic polyacrylamide flocculant and its application for water flocculation. Int. J. Biol. Macromol. 146, 9-17. doi: 10.1016/j.ijbiomac. 2019.12.245

Chen, S., Wang, G., Sui, W., Parvez, A. M., Dai, L., and Si, C. (2020b). Novel lignin-based phenolic nanosphere supported palladium nanoparticles with highly efficient catalytic performance and good reusability. Ind. Crop Prod. 145:112164. doi: 10.1016/j.indcrop.2020.112164

Chen, S., Wang, G., Sui, W., Parvez, A. M., and Si, C. (2020c). Synthesis of ligninfunctionalized phenolic nanosphere supported $\mathrm{Ag}$ nanoparticles with excellent dispersion stability and catalytic performance. Green Chem. 22, 2879-2888. doi: $10.1039 / \mathrm{c} 9 \mathrm{gc04311j}$

Chen, X., Yang, Q., Si, C. L., Wang, Z., Huo, D., Hong, Y., et al. (2016). Recovery of oligosaccharides from prehydrolysis liquors of poplar by microfiltration/ultrafiltration membranes and anion exchange resin. ACS Sustain. Chem. Eng. 4, 937-943. doi: 10.1021/acssuschemeng.5b01029
T-HK, KL, S-EC, and CS: writing - review and editing. All authors contributed to the article and approved the submitted version.

\section{FUNDING}

This research was supported by the cultivating excellent doctoral dissertation of forestry engineering (LYGCYB202011) and the Technology Development Program (S3030198) funded by the Ministry of SMEs and Startups (MSS, South Korea), and this work was also partially supported by R\&D Program for Forest Science Technology (2019151D10-2023-0301) provided by Korea Forest Service (Korea Forestry Promotion Institute) to S-EC.

Chio, C., Sain, M., and Qin, W. (2019). Lignin utilization: a review of lignin depolymerization from various aspects. Renew. Sustain. Energy Rev. 107, 232249. doi: 10.1016/j.rser.2019.03.008

Dai, L., Ma, M. S., Xu, J. K., Si, C. L., Wang, X. H., Liu, Z., et al. (2020). All-ligninbased hydrogel with fast $\mathrm{pH}$-stimuli responsiveness for mechanical switching and actuation. Chem. Mater. 32, 4324-4330. doi: 10.1021/acs.chemmater. 0c01198

Dai, L., Zhu, W., Lu, J., Kong, F., Si, C. L., and Ni, Y. (2019). A lignin-containing cellulose hydrogel for lignin fractionation. Green Chem. 21, 5222-5230. doi: 10.1039/c9gc01975h

Dai, Z., Ren, P. G., He, W. W., Hou, X., Ren, F., Zhang, Q., et al. (2020). Boosting the electrochemical performance of nitrogen-oxygen co-doped carbon nanofibers based supercapacitors through esterification of lignin precursor. Renew. Energy 162, 613-623. doi: 10.1016/j.renene.2020.07.152

Decostanzi, M., Auvergne, R., Boutevin, B., and Caillol, S. (2019). Biobased phenol and furan derivative coupling for the synthesis of functional monomers. Green Chem. 21, 724-747. doi: 10.1039/c8gc03541e

Deuss, P. J., Scott, M., Tran, F., Westwood, N. J., de Vries, J. G., and Barta, K. (2015). Aromatic monomers by in situ conversion of reactive intermediates in the acid-catalyzed depolymerization of lignin. J. Am. Chem. Soc. 137, 7456-7467. doi: 10.1021/jacs.5b03693

Dong, H. L., Li, M., Jin, Y. C., Wu, Y., Huang, C. X., and Yang, J. L. (2020). Preparation of graphene-like porous carbons with enhanced thermal conductivities from lignin nano-particles by combining hydrothermal carbonization and pyrolysis. Front. Energy Res. 8:148. doi: 10.3389/fenrg.2020. 00148

Du, H., Liu, W., Zhang, M., Si, C., Zhang, X., and Li, B. (2019). Cellulose nanocrystals and cellulose nanofibrils based hydrogels for biomedical applications. Carbohydr. Polym. 209, 130-144. doi: 10.1016/j.carbpol.2019. 01.020

El Mansouri, N. E., and Salvado, J. (2006). Structural characterization of technical lignins for the production of adhesives: application to lignosulfonate, kraft, soda-anthraquinone, organosolv and ethanol process lignins. Ind. Crops Prod. 24, 8-16. doi: 10.1016/j.indcrop.2005.10.002

Figueiredo, P., Ferro, C., Kemell, M., Liu, Z., Kiriazis, A., Lintinen, K., et al. (2017). Functionalization of carboxylated lignin nanoparticles for targeted and pH-responsive delivery of anticancer drugs. Nanomedicine 12, 2581-2596. doi: 10.2217/nnm-2017-0219

Gan, L. H., and Pan, X. J. (2019). Phenol-enhanced depolymerization and activation of kraft lignin in alkaline medium. Ind. Eng. Chem. Res. 58, 77947800. doi: 10.1021/acs.iecr.9b01147

Gao, C., Xiao, L. P., Zhou, J. H., Wang, H. S., Zhai, S. R., and An, Q. D. (2021). Immobilization of nanosilver onto glycine modified lignin hydrogel composites for highly efficient p-nitrophenol hydrogenation. Chem. Eng. J. 403:126370. doi: $10.1016 /$ j.cej.2020.126370

Garcia Calvo-Flores, F., and Dobado, J. A. (2010). Lignin as renewable raw material. Chemsuschem 3, 1227-1235. doi: 10.1002/cssc.201000157 
Garcia-Mateos, F. J., Cordero-Lanzac, T., Berenguer, R., Morallon, E., Cazorla-Amoros, D., Rodriguez-Mirasol, J., et al. (2017). Lignin-derived Pt supported carbon (submicron)fiber electrocatalysts for alcohol electrooxidation. Appl. Catal. B Environ. 211, 18-30. doi: 10.1016/j.apcatb.2017.04. 008

Garcia-Mateos, F. J., Ruiz-Rosas, R., Rosas, J. M., Rodriguez-Mirasol, J., and Cordero, T. (2019). Controlling the composition, morphology, porosity, and surface chemistry of lignin-based electrospun carbon materials. Front. Mater. 6:114. doi: 10.3389/fmats.2019.00114

Guo, K., Gao, B., Yue, Q., Xu, X., Li, R., and Shen, X. (2018). Characterization and performance of a novel lignin-based flocculant for the treatment of dye wastewater. Int. Biodeterior. Biodegradation 133, 99-107. doi: 10.1016/j.ibiod. 2018.06.015

Han, X., Lv, Z., Ran, F., Dai, L., Li, C., and Si, C. L. (2021). Green and stable piezoresistive pressure sensor based on lignin-silver hybrid nanoparticles/polyvinyl alcohol hydrogel. Int. J. Biol. Macromol. 176, 78-86. doi: 10.1016/j.ijbiomac.2021.02.055

He, S., Shi, G. B., Xiao, H., Sun, G. X., Shi, Y. J., Chen, G. Y., et al. (2021). Self S-doping activated carbon derived from lignin-based pitch for removal of gaseous benzene. Chem. Eng. J. 410:128286. doi: 10.1016/j.cej.2020.12 8286

Hochegger, M., Trimmel, G., Cottyn-Boitte, B., Cezard, L., Majira, A., Schober, S., et al. (2019). Influence of base-catalyzed organosolv fractionation of larch wood sawdust on fraction yields and lignin properties. Catalysts 9:20. doi: $10.3390 /$ catal9120996

Huang, C. X., Dong, H. L., Zhang, Z. P., Bian, H. Y., and Yong, Q. (2020). Procuring the nano-scale lignin in prehydrolyzate as ingredient to prepare cellulose nanofibril composite film with multiple functions. Cellulose 27, 9355-9370. doi: 10.1007/s10570-020-03427-9

Huang, C. X., He, J., Narron, R., Wang, Y. H., and Yong, Q. (2017). Characterization of kraft lignin fractions obtained by sequential ultrafiltration and their potential application as a biobased component in blends with polyethylene. ACS Sustain. Chem. Eng. 5, 11770-11779. doi: 10.1021/ acssuschemeng.7b03415

Jiao, G.-J., Ma, J., Li, Y., Jin, D., Guo, Y., Zhou, J., et al. (2021). Enhanced adsorption activity for phosphate removal by functional lignin-derived carbon-based adsorbent: optimization, performance and evaluation. Sci. Total Environ. 761:143217. doi: 10.1016/j.scitotenv.2020.14 3217

Jin, C., Song, W., Liu, T., Xin, J., Hiscox, W. C., Zhang, J., et al. (2018). Temperature and $\mathrm{pH}$ responsive hydrogels using methacrylated lignosulfonate cross-linker: synthesis, characterization, and properties. ACS Sustain. Chem. Eng. 6, 17631771. doi: 10.1021/acssuschemeng.7b03158

Kang, C., Huang, Y., Yang, H., Yan, X. F., and Chen, Z. P. (2020). A review of carbon dots produced from biomass wastes. Nanomaterials 10:2316. doi: $10.3390 /$ nano 10112316

Kazzaz, A. E., Feizi, Z. H., and Fatehi, P. (2019). Grafting strategies for hydroxy groups of lignin for producing materials. Green Chem. 21, 5714-5752. doi: $10.1039 / \mathrm{c} 9 \mathrm{gc0} 2598 \mathrm{~g}$

Li, J. J., Zhang, J. Z., Zhang, S. F., Gao, Q., Li, J. Z., and Zhang, W. (2018). Alkali lignin depolymerization under eco-friendly and cost-effective $\mathrm{NaOH} /$ urea aqueous solution for fast curing bio-based phenolic resin. Ind. Crops Prod. 120, 25-33. doi: 10.1016/j.indcrop.2018.04.027

Li, N., Hu, Y. J., Bian, J., Li, M. F., Hao, X., Peng, F., et al. (2020). Enhanced mechanical performance of xylan-based composite hydrogel via chain extension and semi-interpenetrating networks. Cellulose 27, 4407-4416. doi: 10.1007/s10570-020-03080-2

Li, S. X., Li, M. F., Bian, J., Wu, X. F., Peng, F., and Ma, M. G. (2019). Preparation of organic acid lignin submicrometer particle as a natural broad-spectrum photoprotection agent. Int. J. Biol. Macromol. 132, 836-843. doi: 10.1016/j.ijbiomac. 2019.03.177

Li, T., and Takkellapati, S. (2018). The current and emerging sources of technical lignins and their applications. Biofuel. Bioprod. Biorefin. 12, 756-787. doi: 10. 1002/bbb.1913

Li, X., Xu, R., Yang, J., Nie, S., Liu, D., Liu, Y., et al. (2019). Production of 5-hydroxymethylfurfural and levulinic acid from lignocellulosic biomass and catalytic upgradation. Ind. Crops Prod. 130, 184-197. doi: 10.1016/j.indcrop. 2018.12.082
Li, Y. J., Li, F., Yang, Y., Ge, B. C., and Meng, F. Z. (2021). Research and application progress of lignin-based composite membrane. J. Polym. Eng. 41, 245-258. doi: 10.1515/polyeng-2020-0268

Li, Y., Wu, M., Wang, B., Wu, Y., Ma, M. G., and Zhang, X. (2016). Synthesis of magnetic lignin-based hollow microspheres: a highly adsorptive and reusable adsorbent derived from renewable resources. ACS Sustain. Chem. Eng. 4, 5523-5532. doi: 10.1021/acssuschemeng.6b01244

Lievonen, M., Valle-Delgado, J. J., Mattinen, M. L., Hult, E. L., Lintinen, K., Kostiainen, M. A., et al. (2016). A simple process for lignin nanoparticle preparation. Green Chem. 18, 1416-1422. doi: 10.1039/c5gc01 $436 \mathrm{k}$

Liu, H., Xu, T., Liu, K., Zhang, M., Liu, W., Li, H., et al. (2021). Ligninbased electrodes for energy storage application. Ind. Crops Prod. 165:113425. doi: 10.1016/j.indcrop.2021.113425

Liu, K., Du, H., Zheng, T., Liu, H., Zhang, M., Zhang, R., et al. (2021). Recent advances in cellulose and its derivatives for oilfield applications. Carbohydr. Polym. 259:117740. doi: 10.1016/j.carbpol.2021.117740

Liu, R., Dai, L., Xu, C., Wang, K., Zheng, C., and Si, C. (2020). Lignin-based micro- and nanomaterials and their composites in biomedical applications. ChemSusChem 13, 4266-4283. doi: 10.1002/cssc.202000783

Liu, S., and Ma, M. G. (2020). Lignin-derived nitrogen-doped polyacrylonitrile/polyaniline carbon nanofibers by electrospun method for energy storage. Ionics 26, 4651-4660. doi: 10.1007/s11581-020-03603-8

Liu, W., Du, H., Zhang, M., Liu, K., Liu, H., Xie, H., et al. (2020). Bacterial cellulosebased composite scaffolds for biomedical applications: a review. ACS Sustain. Chem. Eng. 8, 7536-7562. doi: 10.1021/acssuschemeng.0c00125

Liu, W., Du, H., Liu, K., Liu, H., Xie, H., Si, C., et al. (2021). Sustainable preparation of cellulose nanofibrils via choline chloride-citric acid deep eutectic solvent pretreatment combined with high-pressure homogenization. Carbohydr. Polym. 267:118220. doi: 10.1016/j.carbpol.2021.118220

Liu, Y. J., Cao, W. T., Ma, M. G., and Wan, P. B. (2017). Ultrasensitive wearable soft strain sensors of conductive, self-healing, and elastic hydrogels with synergistic "soft and hard" hybrid networks. ACS Appl. Mater. Interfaces 9, 25559-25570. doi: $10.1021 /$ acsami.7b07639

Luis Espinoza-Acosta, J., Torres-Chavez, P. I., Olmedo-Martinez, J. L., Vega-Rios, A., Flores-Gallardo, S., and Armando Zaragoza-Contreras, E. (2018). Lignin in storage and renewable energy applications: a review. J. Energy Chem. 27, 1422-1438. doi: 10.1016/j.jechem.2018.02.015

Ma, C., Yuan, Q., Du, H., Ma, M. G., Si, C., and Wan, P. (2020). Multiresponsive MXene $\left(\mathrm{Ti}_{3} \mathrm{C}_{2} \mathrm{~T}_{x}\right)$-decorated textiles for wearable thermal management and human motion monitoring. ACS Appl. Mater. Interfaces, 12, 34226-34234. doi: 10.1021/acsami.0c10750

Ma, C. Y., Gao, X., Peng, X. P., Gao, Y. F., Liu, J., Wen, J. L., et al. (2021a). Microwave-assisted deep eutectic solvents (DES) pretreatment of control and transgenic poplars for boosting the lignin valorization and cellulose bioconversion. Ind. Crops Prod. 164:113415. doi: 10.1016/j.indcrop.2021. 113415

Ma, C., Mei, X., Fan, Y., and Zhang, Z. (2018). Oxidative depolymerizaton of kraft lignin and its application in the synthesis of lignin-phenol-formaldehyde resin. Bioresources 13, 1223-1234. doi: 10.15376/biores.13.1.1223-1234

Ma, C., Ma, M. G., Si, C., Ji, X. X., and Wang, P. (2021b). Flexible MXene-based composites for wearable devices. Adv. Funct. Mater. 2009524. doi: 10.1002/ adfm.202009524

Ma, C., Wu, L. Q., Dirican, M., Cheng, H., Li, J. J., Song, Y., et al. (2021c). ZnOassisted synthesis of lignin-based ultra-fine microporous carbon nanofibers for supercapacitors. J. Colloid Interface Sci. 586, 412-422. doi: 10.1016/j.jcis.2020. 10.105

Meng, L. Y., Ma, M. G., and Ji, X. X. (2019). Preparation of lignin-based carbon materials and its application as a sorbent. Materials 12:1111. doi: 10.3390/ ma12071111

Meng, Y., Lu, J., Cheng, Y., Li, Q., and Wang, H. (2019). Lignin-based hydrogels: a review of preparation, properties, and application. Int. J. Biol. Macromol. 135, 1006-1019. doi: 10.1016/j.ijbiomac.2019.05.198

Naseem, A., Tabasum, S., Zia, K. M., Zuber, M., Ali, M., and Noreen, A. (2016). Lignin-derivatives based polymers, blends and composites: a review. Int. J. Biol. Macromol. 93, 296-313. doi: 10.1016/j.ijbiomac.2016.08.030

Nguyen, N. A., Barnes, S. H., Bowland, C. C., Meek, K. M., Littrell, K. C., Keum, J. K., et al. (2018a). A path for lignin valorization via additive manufacturing of 
high-performance sustainable composites with enhanced 3D printability. Sci. Adv. 4:eaat4967. doi: 10.1126/sciadv.aat 4967

Nguyen, N. A., Bowland, C. C., and Naskar, A. K. (2018b). General method to improve 3D-printability and inter-layer adhesion in lignin-based composites. Appl. Mater. Today 12, 138-152. doi: 10.1016/j.apmt.2018.03.009

Pang, B., Cao, X. F., Sun, S. N., Wang, X. L., Wen, J. L., Lam, S. S., et al. (2020). The direct transformation of bioethanol fermentation residues for production of high-quality resins. Green Chem. 22, 439-447. doi: 10.1039/c9gc03 $568 \mathrm{k}$

Pang, B., Yang, S., Fang, W., Yuan, T. Q., Argyropoulos, D. S., and Sun, R. C. (2017). Structure-property relationships for technical lignins for the production of lignin-phenol-formaldehyde resins. Ind. Crops Prod. 108, 316-326. doi: 10. 1016/j.indcrop.2017.07.009

Pei, W. H., Shang, W. Q., Liang, C., Jiang, X., Huang, C. X., and Yong, Q. (2020). Using lignin as the precursor to synthesize $\mathrm{Fe}_{3} \mathrm{O}_{4} @$ lignin composite for preparing electromagnetic wave absorbing lignin-phenol-formaldehyde adhesive. Ind. Crops Prod. 154:112634. doi: 10.1016/j.indcrop.2020.11 2638

Qian, Y., Zhou, Y., Lu, M., Guo, X., Yang, D., Lou, H., et al. (2021). Direct construction of catechol lignin for engineering long-acting conductive, adhesive, and UV-blocking hydrogel bioelectronics. Small Methods 5:2001311. doi: 10.1002/smtd.202001311

Ragauskas, A. J., Beckham, G. T., Biddy, M. J., Chandra, R., Chen, F., Davis, M. F., et al. (2014). Lignin valorization: improving lignin processing in the biorefinery. Science 344:1246843. doi: $10.1126 /$ science. 1246843

Saha, D., Li, Y., Bi, Z., Chen, J., Keum, J. K., Hensley, D. K., et al. (2014). Studies on supercapacitor electrode material from activated lignin-derived mesoporous carbon. Langmuir 30, 900-910. doi: 10.1021/la404112m

Sen, S., Patil, S., and Argyropoulos, D. S. (2015). Thermal properties of lignin in copolymers, blends, and composites: a review. Green Chem. 17, 4862-4887. doi: $10.1039 / \mathrm{c} 5 \mathrm{gc} 01066 \mathrm{~g}$

Shen, X. J., Wen, J. L., Mei, Q. Q., Chen, X., Sun, D., Yuan, T. Q., et al. (2019). Facile fractionation of lignocelluloses by biomass-derived deep eutectic solvent (DES) pretreatment for cellulose enzymatic hydrolysis and lignin valorization. Green Chem. 21, 275-283. doi: 10.1039/c8gc03064b

Shi, Z. J., and Ma, M. G. (2019). Synthesis, structure, and applications of ligninbased carbon materials: a review. Sci. Adv. Mater. 11, 18-32. doi: 10.1166/sam. 2019.3382

Si, C. (2019). The Development of lignocellulosic biomass in medicinal applications. Curr. Med. Chem. 26, 2408-2409. doi: 10.2174/ 092986732614190724160641

Solt, P., Rossiger, B., Konnerth, J., and van Herwijnen, H. W. G. (2018). Lignin phenol formaldehyde resoles using base-catalysed depolymerized kraft lignin. Polymers 10:1162. doi: 10.3390/polym 10101162

Suhas, Carrott, P. J. M., and Carrott, M. M. L. R. (2007). Lignin- from natural adsorbent to activated carbon: a review. Bioresour. Technol. 98, 2301-2312. doi: 10.1016/j.biortech.2006.08.008

Sun, S. L., Wen, J. L., Ma, M. G., and Sun, R. C. (2014). Structural elucidation of sorghum lignins from an integrated biorefinery process based on hydrothermal and alkaline treatments. J. Agric. Food Chem. 62, 8120-8128. doi: 10.1021/ jf501669r

Sun, Y. C., Liu, X. N., Wang, T. T., Xue, B. L., and Sun, R. C. (2019). Green process for extraction of lignin by the microwave-assisted ionic liquid approach: toward biomass biorefinery and lignin characterization. ACS Sustain. Chem. Eng. 7, 13062-13072. doi: 10.1021/acssuschemeng.9b02166

Sutton, J. T., Rajan, K., Harper, D. P., and Chmely, S. C. (2018). Lignin-containing photoactive resins for 3D printing by stereolithography. ACS Appl. Mater. Interfaces 10, 36456-36463. doi: 10.1021/acsami.8b13031

Thakur, V. K., and Thakur, M. K. (2015). Recent advances in green hydrogels from lignin: a review. Int. J. Biol. Macromol. 72, 834-847. doi: 10.1016/j.ijbiomac. 2014.09.044

Upton, B. M., and Kasko, A. M. (2016). Strategies for the conversion of lignin to high-value polymeric materials: review and perspective. Chem. Rev. 116, 2275-2306. doi: 10.1021/acs.chemrev.5b00345

Venkatesagowda, B., and Dekker, R. F. H. (2020). Enzymatic demethylation of Kraft lignin for lignin-based phenol-formaldehyde resin applications. Biomass Convers. Biorefin. 10, 203-225. doi: 10.1007/s13399-019-00407-3
Vishtal, A., and Kraslawski, A. (2011). Challenges in industrial applications of technical lignins. Bioresources 6, 3547-3568.

Wan, X., Shen, F., Hu, J., Huang, M., Zhao, L., Zeng, Y., et al. (2021). 3-D hierarchical porous carbon from oxidized lignin by one-step activation for highperformance supercapacitor. Int. J. Biol. Macromol. 180, 51-60. doi: 10.1016/j. ijbiomac.2021.03.048

Wang, B., Wang, H. M., Sun, D., Yuan, T. Q., Song, G. Y., Shi, Q., et al. (2020a). Chemosynthesis, characterization and application of lignin-based flocculants with tunable performance prepared by short-wavelength ultraviolet initiation. Ind. Crops Prod. 157:112897. doi: 10.1016/j.indcrop.2020.112897

Wang, B., Wang, S. F., Lam, S. S., Sonne, C., Yuan, T. Q., Song, G. Y., et al. (2020b). A review on production of lignin-based flocculants: sustainable feedstock and low carbon footprint applications. Renew. Sustain. Energy Rev. 134:110384. doi: 10.1016/j.rser.2020.110384

Wang, G., Liu, X., Zhang, J., Sui, W., Jang, J., and Si, C. L. (2018). One-pot lignin depolymerization and activation by solid acid catalytic phenolation for lightweight phenolic foam preparation. Ind. Crops Prod. 124, 216-225. doi: 10.1016/j.indcrop.2018.07.080

Wang, H., Du, H., Liu, K., Liu, H., Xu, T., Zhang, S., et al. (2021). Sustainable preparation of bifunctional cellulose nanocrystals via mixed $\mathrm{H}_{2} \mathrm{SO}_{4}$ /formic acid hydrolysis. Carbohydr. Polym. 266:118107. doi: 10.1016/j.carbpol.2021.118107

Wang, S. R., Wang, K. G., Liu, Q., Gu, Y. L., Luo, Z. Y., Cen, K. F., et al. (2009). Comparison of the pyrolysis behavior of lignins from different tree species. Biotechnol. Adv. 27, 562-567. doi: 10.1016/j.biotechadv.2009.04.010

Witzler, M., Alzagameem, A., Bergs, M., El Khaldi-Hansen, B., Klein, S. E., Hielscher, D., et al. (2018). Lignin-derived biomaterials for drug release and tissue engineering. Molecules 23:1885. doi: 10.3390/molecules23081885

Woermeyer, K., Ingram, T., Saake, B., Brunner, G., and Smirnova, I. (2011). Comparison of different pretreatment methods for lignocellulosic materials. Part II: influence of pretreatment on the properties of rye straw lignin. Bioresour. Technol. 102, 4157-4164. doi: 10.1016/j.biortech.2010.11.063

Xi, Y. B., Yang, D. J., Lou, H. M., Gong, Y. Y., Yi, C. H., Lyu, G. J., et al. (2021). Designing the effective microstructure of lignin-based porous carbon substrate to inhibit the capacity decline for $\mathrm{SnO}_{2}$ anode. Ind. Crops Prod. 161:113179. doi: 10.1016/j.indcrop.2020.113179

Xiong, S. J., Bo, P., Zhou, S. J., Li, M. K., Yang, S., Wang, Y. Y., et al. (2020). Economically competitive biodegradable PBAT/lignin composites: effect of lignin methylation and compatibilizer. ACS Sustain. Chem. Eng. 8, 5338-5346. doi: 10.1021/acssuschemeng.0c00789

Xu, J., Li, C., Dai, L., Xu, C., Zhong, Y., Yu, F., et al. (2020). Biomass fractionation and lignin fractionation towards lignin valorization. ChemSusChem 13, 42844295. doi: $10.1002 /$ cssc.202001491

Xu, J., Shao, Z., Li, Y., Dai, L., Wang, Z., and Si, C. (2021). A flow-through reactor for fast fractionation and production of structure-preserved lignin. Ind. Crops Prod. 164:113350. doi: 10.1016/j.indcrop.2021.113350

Xu, Q. Q., Wang, X., Cheng, J., Zhang, L., He, F., and Xie, H. B. (2020). Self-template/activation nitrogen-doped porous carbon materials derived from lignosulfonate-based ionic liquids for high performance supercapacitors. RSC Adv. 10, 36504-36513. doi: 10.1039/d0ra06821g

Xu, X. Y., Ray, R., Gu, Y. L., Ploehn, H. J., Gearheart, L., Raker, K., et al. (2004). Electrophoretic analysis and purification of fluorescent single-walled carbon nanotube fragments. J. Am. Chem. Soc. 126, 12736-12737. doi: 10.1021/ ja040082h

Yang, X., Xie, H., Du, H., Zhang, X., Zou, Z., Zou, Y., et al. (2019). Facile extraction of thermally stable and dispersible cellulose nanocrystals with high yield via a green and recyclable $\mathrm{FeCl}_{3}$-catalyzed deep eutectic solvent system. ACS Sustain. Chem. Eng. 7, 7200-7208. doi: 10.1021/acssuschemeng.9b00209

Yang, X. X., Guo, Y. Z., Liang, S., Hou, S. Y., Chu, T. T., Ma, J. L., et al. (2020). Preparation of sulfur-doped carbon quantum dots from lignin as a sensor to detect Sudan I in an acidic environment. J. Mater. Chem. B 8, 10788-10796. doi: $10.1039 / \mathrm{d} 0 \mathrm{tb} 00125 \mathrm{~b}$

Yu, O., and Kim, K. H. (2020). Lignin to materials: a focused review on recent novel lignin applications. Appl. Sci. 10:4626. doi: 10.3390/app10134626

Zhang, B. H., Liu, Y. J., Ren, M. Q., Li, W. T., Zhang, X., Vajtai, R., et al. (2019). Sustainable synthesis of bright green fluorescent nitrogen-doped carbon quantum dots from alkali lignin. Chemsuschem 12, 4202-4210. doi: 10.1002/ cssc. 201901693 
Zhang, W., Yin, J., Lin, Z., Lin, H., Lu, H., Wang, Y., et al. (2015a). Facile preparation of $3 \mathrm{D}$ hierarchical porous carbon from lignin for the anode material in lithium ion battery with high rate performance. Electrochim. Acta 176, 1136-1142. doi: 10.1016/j.electacta.2015.08.001

Zhang, W., Zhao, M., Liu, R., Wang, X., and Lin, H. (2015b). Hierarchical porous carbon derived from lignin for high performance supercapacitor. Colloids Surf. A Physicochem. Eng. Asp. 484, 518-527. doi: 10.1016/j.colsurfa.2015. 08.030

Zhang, Y. W., Yuan, B., Zhang, Y. Q., Cao, Q. P., Yang, C., Li, Y., et al. (2020). Biomimetic lignin/poly(ionic liquids) composite hydrogel dressing with excellent mechanical strength, self-healing properties, and reusability. Chem. Eng. J. 400:125984. doi: 10.1016/j.cej.2020.125984

Zhao, S., and Abu-Omar, M. M. (2021). Materials based on technical bulk lignin. ACS Sustain. Chem. Eng. 9, 1477-1493. doi: 10.1021/acssuschemeng.0c08882

Zheng, L., Yu, P., Zhang, Y., Wang, P., Yan, W., Guo, B., et al. (2021). Evaluating the bio-application of biomacromolecule of lignin-carbohydrate complexes (LCC) from wheat straw in bone metabolism via ROS scavenging.
Int. J. Biol. Macromol. 176, 13-25. doi: 10.1016/j.ijbiomac.2021.01. 103

Zhu, J. D., Yan, C. Y., Zhang, X., Yang, C., Jiang, M. J., and Zhang, X. W. (2020). A sustainable platform of lignin: from bioresources to materials and their applications in rechargeable batteries and supercapacitors. Prog. Energy Combust. Sci. 76:100788. doi: 10.1016/j.pecs.2019.100788

Conflict of Interest: The authors declare that the research was conducted in the absence of any commercial or financial relationships that could be construed as a potential conflict of interest.

Copyright (c) $2021 \mathrm{Ma}$, Kim, Liu, Ma, Choi and Si. This is an open-access article distributed under the terms of the Creative Commons Attribution License (CC BY). The use, distribution or reproduction in other forums is permitted, provided the original author(s) and the copyright owner(s) are credited and that the original publication in this journal is cited, in accordance with accepted academic practice. No use, distribution or reproduction is permitted which does not comply with these terms. 